\title{
A Figurativização na Publicidade
}

\section{Leonilda Ranzani de Luca}

Para se compreender a figurativização dos discursos, bem como os procedimentos mobilizados pelo enunciador para tal, é necessário "a construção de um simulacro de produção de discurso, ou seja, refazer o percurso gerativo do sentido via enunciado e enunciação enunciada".

Segundo Greimas (1983: 185-186), a construção desse simulacro é que nos dá "o quadro geral, no interior do qual se pode procurar inscrever, de maneira operatória e provisória, os procedimentos de figurativização de um discurso, colocado a princípio como neutro e abstrato".

Tendo isso em vista, procuraremos, neste artigo, mostrar a relação entre a figuratividade/figurativização (Greimas c Courtés, 1986: 91) de textos publicitários da media impressa e certas instâncias do percurso gerativo, procurando dar uma idéia de como a figuratividade/figurativizaçāo "brota" e "florescè" a partir dos valores da estrutura profunda atè a manifestação, dando maior ênfase aos niveis narrativo e discursivo, e arriscando uma brcve incursão pelo percurso gerativo da expressão.

Ler um texto publicitárioé tarefa relativamente fácil, desde que se leve em conta a intertextualidade, enquanto textos-ocorrência de um mesmouniverso de discurso.

As estruturas semióticas desse tipo de discurso estão profundamente enraizadas na competência do leitor - embora possa não se ter consciência disso - e só podem ser apreensiveis na intertextualidade. 
Por esta razão, o sujeito-enunciador (produtor) pode:

(a) implicitar ao máximo as estruturas jemióticas de um texto, tendo em vista a manipulação ou c economia discursiva, ou

(b) explicitar, até ḋ iconização são-sulpiciana, determinadas estruturas, tendo em vista a persuasão sobre o leitor.

No anúncio da Du Loren (fig.1), temos um caso te implicitaçāo tendendo para a maximização, onde o texto manifestado se reduz a três ou quatro figurasator (todas com o mesmo aporte-predicado /feninilidade/): o destinador, o destinatário e os objetos prático e mítico. Esse reduzzido plano de expressão

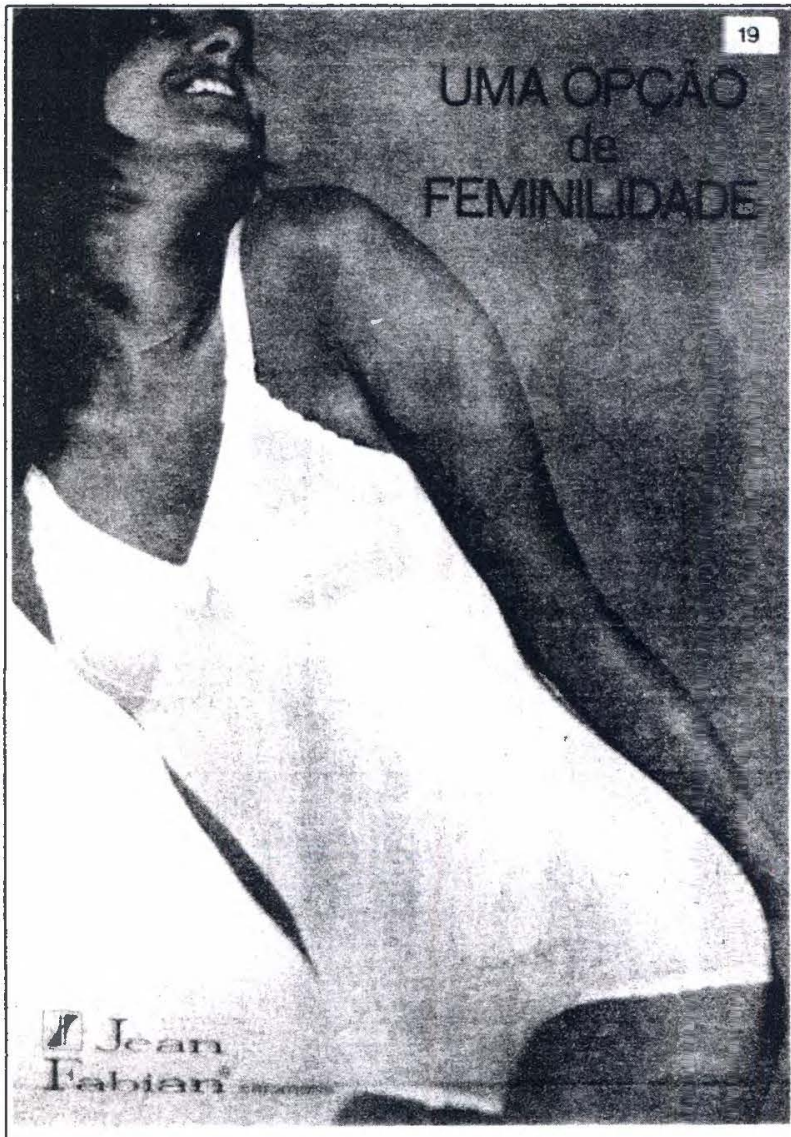

Fig. 1 condensa os percursos de SI (sujeito produtor-enunciador-manipulador) e de S2 (sujeito enunciatário-manipulado), percursos que, em outros textos, podem corresponder a programas narrativos (PN) altamente complexificados. Todavia, em caso de implicitação máxima, o texto publicitário manifestado pode se reduzir à apresentação do objeto, lugar por excelência da intersubjetividade, que pode condensar o percurso dos três sujeitos da propaganda (o S1 e o S2, mencionados acima, $e$ o \$3 que, geralmente, é o sujeito beneficiário), graças à memória intertextual do leitor. Como exemplo de explicitação ten- 
dendo para a maximização, lcmbramos que há textos cm que, além de cxplicitarem os percursos de S1 e S2 (c, por vezes, também o de S3 -- o sujcito bencficiário), com graus variados de complexificação, mostram a refigurativização, no visual, de traços semânticos contextuais que compõcm o aportepredicado das figuras-ator sujeito c objeto, já expressas no verbal. Essa redundância intercódigos, geralmente tem fins persuasivos. Tais refigurativizaçōcs obedecem a procedimentos metafóricos ou metonímicos, na forma de uma narrativa encaixada no texto global. Éoque se pode observar no texto da Colônia Nuage (fig.2), em que a cena da moça andando de bicicleta sob a chuva, num recorte verbal do visual, refigurativiza metaforicamente, no visual, o sema contextual / refrescante/ que compõc - aportc-predicado do ator-objcto Colônia Nuage sob o ponto de vista do processo, ou scja, do tempo aspectualizado.

Já no anúncio da

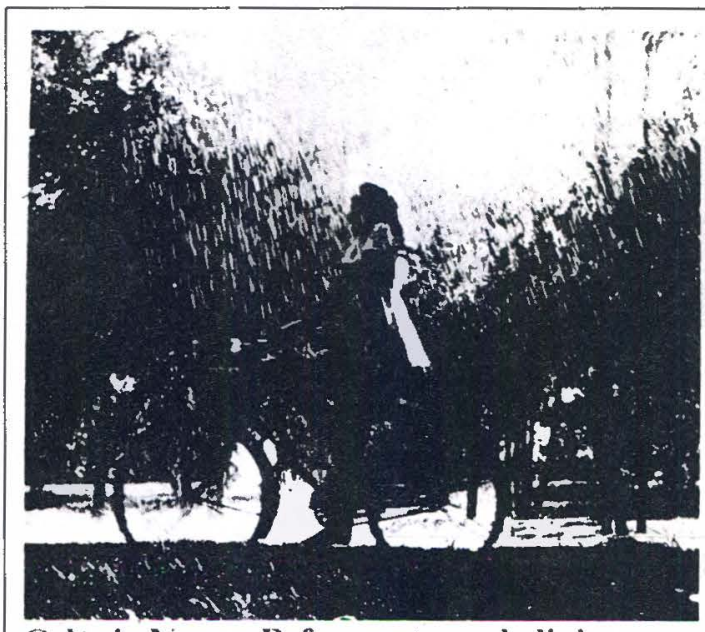

Colonia Vuage. Refrescante e geladinha como un mergulho de corpo inteiro na nature/a.

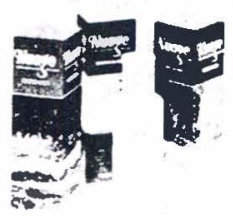

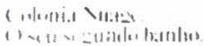

Fig.2 Volkswagen (fig.3), os vários objetos (ou formantes plásticos) refigurativizam, metonimicamente, no visual, traços semânticos que compöem o aporte-predicado do ator-sujeito (S2) expresso no verbal, sob o ponto de vista do estado, ou seja, do cspaço aspectualizado.

Todavia, ainda com fins persuasivos, as refigurativizaçōes podem retomar camadas mais profundas do percurso gerativo. É o caso do anúncio da Lee (fig.4), onde a cena que envolve os jovens refigurativiza metaforicamente, no visual, o PN cuforizado "pintando a vida de Lee", expresso pelo código verbal, enquanto que o quadro O Menino Azul, de Thomas Gainsborough, além de refigurativizar metaforicamentc a virtualização do $\mathrm{PN}$-- nem cufórico,ncm- 


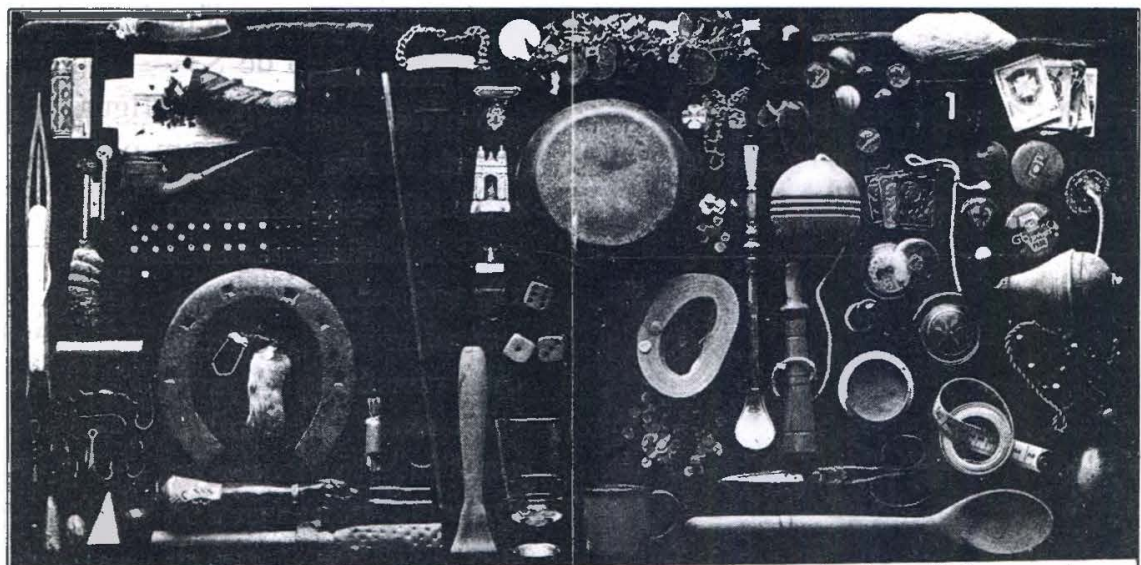

Por mais que variem os gostos, usos e costumes dos brasileiros, um ponto é pacífico: todos gostam de um Volkswagen.

Fig.3

Q. A morcer que conthect

disfórico -. "pintar o mundo de azul", se inscreve como valor no objeto moda lee azul, conotando / nobrcza/e /artc/.

Como sc pode notar por estes poucos excmplos, a implicitação/explicitaçāo de estruturas do plano do contcúdo estão sujcitas a uma gradação que sofre cocrçōes das necessidades manipulatório-persuasivas da comunicaçāo, de um lado, c da compctência discursiva do sujcito cnunciador,de outro.Esses

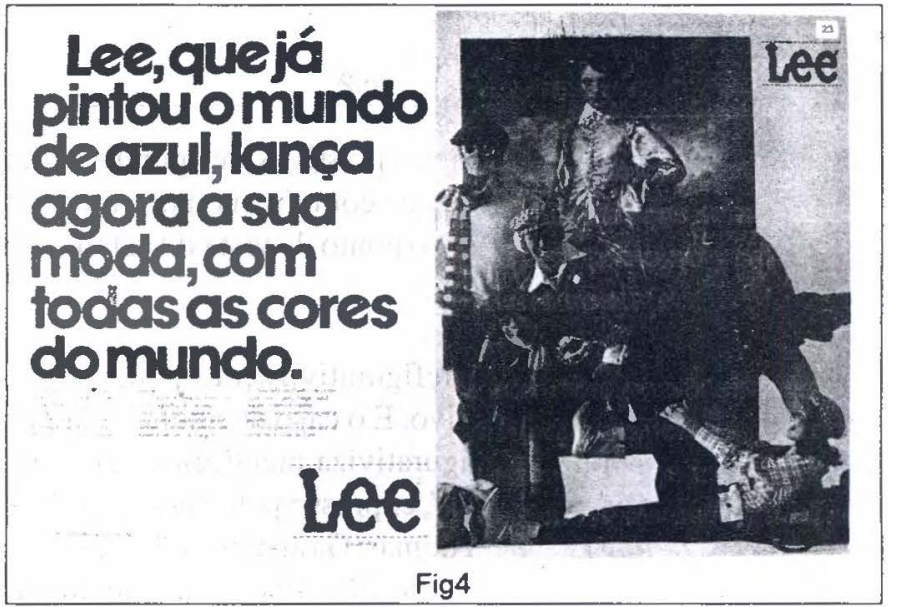

problemas ligados com a cxplosão/rarefação de figuras da cena textual, entretanto, só podem ser entendidos quando sc conhece a estrutura global que cstá por detrás de toda cena textual desse universo 
de discurso.Todo texto publicitário é manifestação integral ou parcial de um contrato entre o sujeito enunciador (fabricante) e o sujeito enunciatário (leitorcomprador e/ou consumidor).

Mostramos, no quadro a seguir (Quadro I), a estrutura narrativa desse contrato, sem no entanto pretender validade universal para esse. esboço de modelo por nós apreendido na intertextualidade.

Não pretendemos fazer aqui uma leitura exaustiva do modelo (conforme Quadro I), pois, se ele tiver alguma validade, falará por si mesmo. Algumas observações, contudo, devem ser feitas sobre o mesmo:

1) de acordo com o algoritmo narrativo, a superfície global de todo texto publicitário (da media impressa, relativo a bens de consumo), pelo fato do mesmo ser um contrato entre enunciador e enunciatário, inscreve-se como fase de manipulação (enunciados III, II, I e 3, 2, 1, que compreendem as estruturas modais e contratuais da manipulação) no PN de base de S2, cuja performance principal, do ponto de vista do anunciante, é a compra do produto enquanto fazer somático diferido no tempo; do ponto de vista do leitorcomprador e/ou consumidor, a compra do produto, por um procedimento retórico da enunciação, desloca-se para a fase da aquisição da competência segundo o poder;

2) nos textos publicitários com estrutura mítica, são negociados dois objetos: a mercadoria (cf.II e 2) e o mito (cf.III e 3). De um lado, o anunciante quer vender uma mercadoria com valor de uso (cf. $\underline{\text { A e }}$ a), porém o leitor não deseja somente objetos de ordem prático-econômica: mais do que isso, ele deseja a realização dos mitos projetados por seus desejos. São estes desejos que $\mathrm{o}$ anunciante propōe realizar (cf. $\underline{\mathrm{B}} \mathrm{e} \underline{\mathrm{b}}$ ):

(a) investindo no objeto prático, valores de essência mítica (cf.드르), através da veiculação de um anúncio (cf.instância da enunciação do modelo); $e$

(b) persuadindo o leitor de que, se este adquirir o produto anunciado, conseguirá a realização dos seus desejos; isto se dá, ao nivel do enunciado + enunciação enunciada, sob a forma de um saber sobre o objeto e sobre a competência do leitor virtual espelhada no seu simulacro discursivo e que é interpretada pelo leitor real ( $c f$. I e I). 


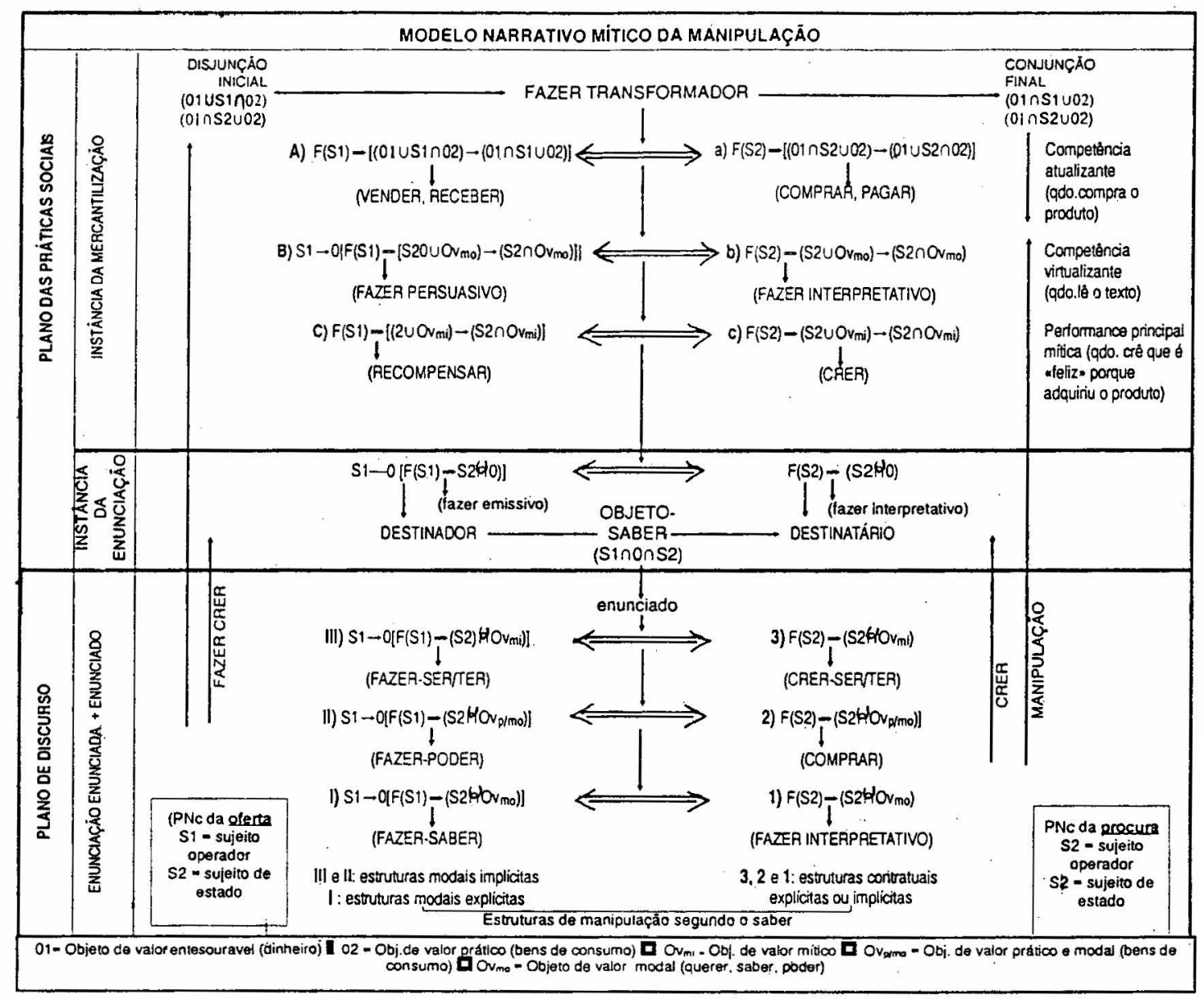

\section{Quadro I}


Para tanto, o anunciante vale-se de uma estratégia discursiva, de caráter retórico, através da qual transforma o PN de base ao modo do ser - que é a compra do produto- em PN de uso ao modo do parecer, necessário à aquisição do objeto mítico. Desta forma, o objeto de ordem prático-econômica (o produto) passa a ter um estatuto modal: representa a modalidade do poder-ser/ter (cf.III c. 3).

No texto publicitário, qualquer enunciado de fazer ou de estado, compreendendo-se aqui todas as fases de cada instância do modelo proposto, são suscetíveis de serem figurativizadas sob o estatuto de um fazer persuasivo, valendo-se ou não de debreagens internas. Isso nos dá uma idéia das possibilidades figurativas do discurso publicitário: podemos imaginar quantos PNs de base e de uso, cada qual com quatro fases (manipulação, competência, performance e sanção) podem ser figurativizados com fins persuasivos, tendo-se em vista a dimensão das práticas sociais que compreende desde a aquisição da matéria-prima, passando pela produção do objeto, até o consumo final do produto, uma vez que o discurso espelha essas práticas. Além disso, o recurso aos procedimentos poéticos criam novas possibilidades de figurativizações.

Todavia, o texto publicitário concentra muito mais a sua figuratividade no percurso de $S 2$ que compreende os enunciados 1, 2 e 3 do modelo proposto, os quais espelham os enunciados $\underline{\mathrm{a}}, \underline{\mathrm{b}} \mathrm{e} \underline{\mathrm{c}}$ tendo-se em vista o plano das práticas sociais.

Faremos, agora, um recorte no modelo, representando os enunciados $\underline{1}, \underline{2}$ e $\underline{3} \mathrm{em}$ forma de esquema (Quadro II) com o fito de melhor especificar a relação entre figurativização $\mathrm{e}$ instâncias do percurso gerativo.

Antes de abordarmos esse esquema, convém observar que, a nível de estrutura profunda, o discurso publicitário propõe como valor último a /ascensão/, no plano individual ou no plano social. Tal /ascensão/ compreende uma escalada por paradigmas míticos hierarquizados que respeitam a competência inicial (anterior à leitura do anúncio) dos diferentes grupos de sujeitos visados pela propaganda, levando em conta as variáveis sócio-econômicoculturais. Dessa forma, se compararmos dois simulacros discursivos de enunciatários do texto publicitário - , veremos que um determinado valor (hipotáxico em relação ao arquétipo dos paradigmas dos valores que é a /ascensão/) a ser alcançado por um sujeito $\underline{A}$, após a aquisição do produto ofertado, pode inscrever-se na competência pressuposta de um sujeito $\underline{B}$, que está num nível 

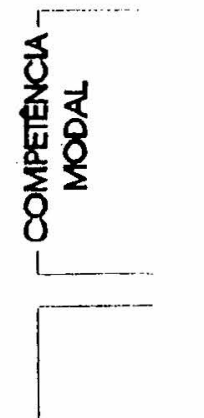
PROVOCAÇÃONATIMIDAÇĀO

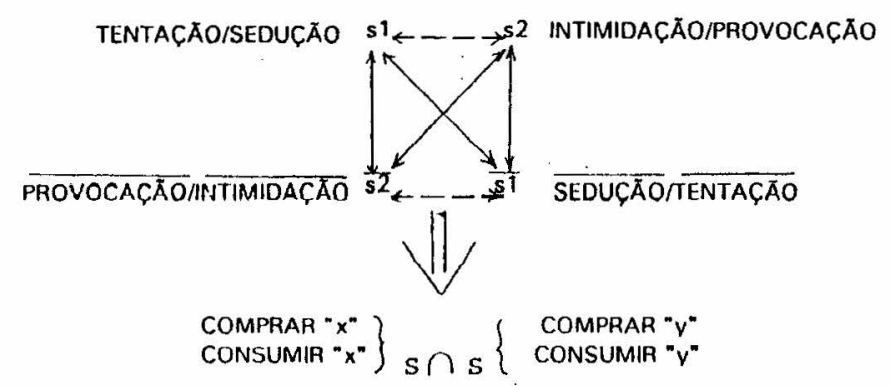

\pm DOAR " $x$ "
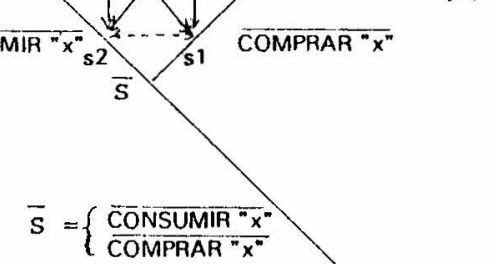

$$
\frac{\text { CONSUMIR " } v^{\prime \prime}}{\text { COMPRAR " } y^{\prime \prime}}=\bar{s}
$$

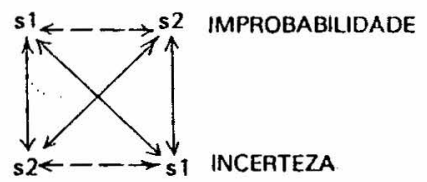

\section{Quadro II}


superior da escala sócio-econômico-cultural. Aos enunciatários que já alcançaram a "felicidade plena», o anunciante propōe a manutenção desse valor, /felicidade/. É o que se pode observar no texto dos cigarros Du Maurier (fig.6).

Representando esse valor arquetípico do discurso publicitário que vende bens de consumo, em termos do quadrado semiótico, temos:

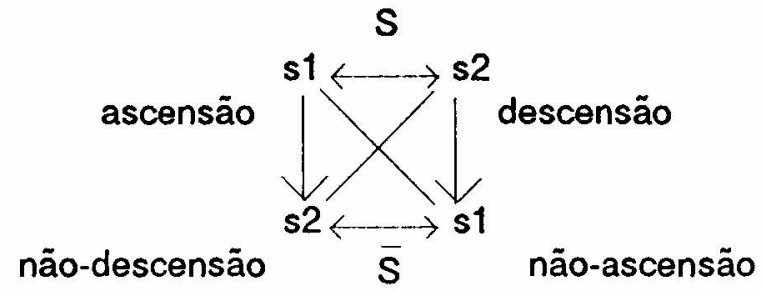

Éa partir da seleção do valor eufórico (s1) e/ou disfórico (s2) que o sujeito enunciador vai figurativizar o seu discurso. A seleção do valor eufórico vai levar à figurativização do PN (comprar+consumir/doar «Y»); a do disfórico, à figurativização do anti-PN (comprar+consumir/doar «X»). Essa é a primeira opção que o sujeito enunciador tem para construir os percursos figurativos do seu texto, determinada, em termos de sintaxe modal, por um não poder-não fazer + querer-fazer_ou um não poder não-fazer + dever-fazer.

Tanto a seleçāo do valor eufórico quanto a do disfórico prestam-se aos fins persuasivos do discurso publicitário (e, provavelmente, de qualquer discurso manipulatório). Assim, o discurso publicitário pode figurativizar:

a) somente o valor eufórico (s1), projetando, a nivel narrativo, o antiPNcomo uma sombra (cf.fig.6);

b) concomitantemente o valor eufórico e disfórico ( 1 e s2), jogando com as relaçōes intercódigos de redundância, complementaridade, oposição (Cf. fig.5);

c) além de s1 e s2, pode também figurativizar os termos complexos:

No anúncio da Lee (fig.4), encontra-se figurativizado, metaforicamente, o termo neutro $(\bar{S})$, através da figura do quadro O Menino Azul. 
Conciliando os valores da estrutura profunda (/ascensão/ e /descensão/), projetados no quadrado semiótico, com o arcabouço narrativo proposto no esquema acima (Quadro II), torna-se mais fácil visualizar, nos textos que

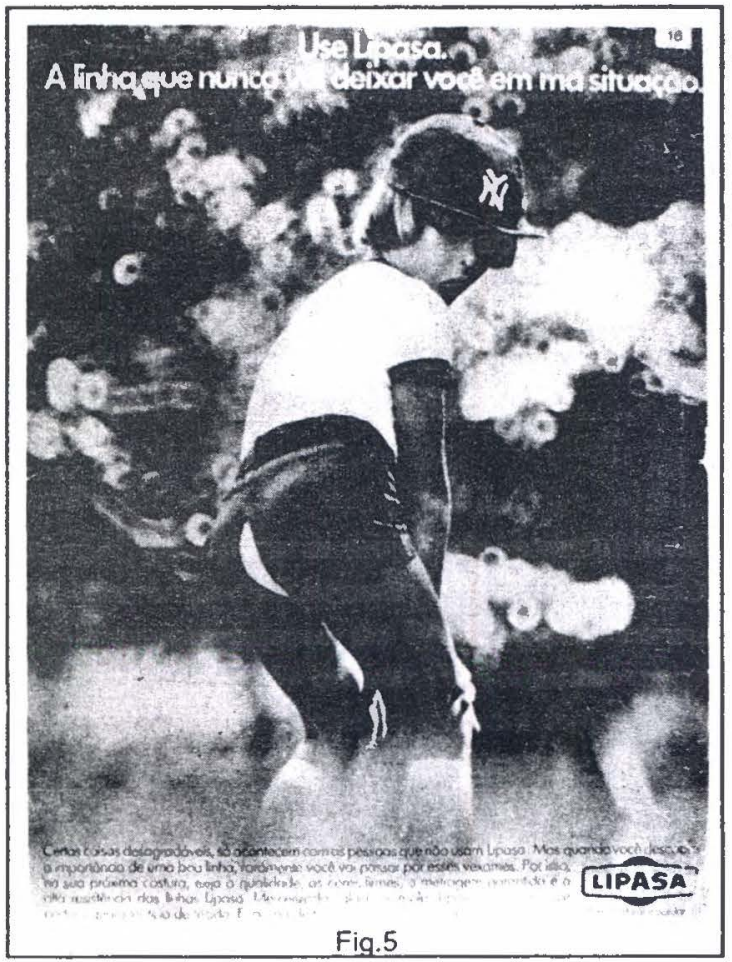
servem de exemplos, quais relações do quadrado e quais percursos narrativos (de S2 e S3) foram figurativizados (Quadro III).

Nos textos da Gerber e dos cigarros $D u$ Maurier, temos a figurativização do PN euforizado (comprar "ry»); notexto das linhas Lipasa, figurativizaram-se o $\mathrm{PN}$ e o anti-PN; já no tex to da Etti (fig.10), embora o contrato proposto seja de natureza idêntica aos demais textos, ele está totalmente implicitado. O que aparece figurativizado é um PN de uso do sujeito Enunciador, ou seja, o PN da produção do objeto e do investimento do valor no objeto. Os enunciados narrativos correspondentes a essa prática social estão fora do modelo global (Quadro 1), pois este tem como ponto de partida a oferta do produto.

Quanto ao esquema (Quadro II), por sua vez, cabe algumas observaçōes:

1) ele comprecnde o percurso de S2 e S3:

- $1^{2}$ quadrado: aquisição da competência de $\$ 2$;

- articulação de quadrados: performance mercantil de S2 e performance mítica de S3;

- $3^{2}$ quadrado:performance mitica de $S 2$ (= a sanção, ou autosanção, do ponto de vista do destinador); 


\begin{tabular}{|c|c|c|}
\hline TEXTO & $\begin{array}{l}\text { A. ATOR + ACTANTE } \\
\text { B- PAPEL TEMATICO }\end{array}$ & $\begin{array}{l}\text { RELAÇÔES DO QUADRADO SEMIÓTICO E PERCURSO } \\
\text { NARRATIVO FIGURATIVIZADOS (CONFORME O ESQUEMA) }\end{array}$ \\
\hline $\begin{array}{l}\text { 3) Gerber } \\
\text { (fig. 7) }\end{array}$ & $\begin{array}{l}\text { A - Mãe : S2 } \\
\text { comprador + } \\
\text { não-consumidor } \\
\text { B - bebê: S3 } \\
\text { consumidor }\end{array}$ & $\begin{array}{l}\text { Não comprar nem consumir "x" ou "y" } \\
(\overline{\mathrm{S}} \cap \overline{\mathrm{S}}) \rightarrow \text { comprar "y" }(\mathrm{s} 1) \longrightarrow \text { doar "y" }(\mathrm{s} 1+\overline{\mathrm{s} 2}) \\
\text { Ganhar "y" } \quad \rightarrow \text { consumir "y" }\end{array}$ \\
\hline $\begin{array}{l}\text { 2) Cigarros } \\
\text { Du Maurier } \\
\text { (fig. 6) }\end{array}$ & $\begin{array}{l}\text { A - Mulher: S2 } \\
\text { B-comprador }+ \\
\text { consumidor }\end{array}$ & Comprar "y" (s1) + consumir "y" (s2) \\
\hline $\begin{array}{l}\text { 1) Linhas } \\
\text { Lipasa } \\
\text { (fig. 5) }\end{array}$ & $\begin{array}{l}\text { A - garoto: } 52 \\
\text { consumidor } \\
\text { B - costureira: } \mathrm{S3} \\
\text { comprador }\end{array}$ & $\begin{array}{l}\text { Consumir "x" }(s 2) \rightarrow \text { não consumir "x" }(\overline{s 2}) \rightarrow \\
\text { ganhar "y" }(s 2+s 1) \rightarrow \text { consumir "y" (s2) } \\
\text { Comprar "x" }(s 1) \rightarrow \text { doar "x" }(s 1+\overline{s 2}) \rightarrow \\
\text { comprar "y" } \rightarrow \text { doar "y" }\end{array}$ \\
\hline
\end{tabular}

\section{Quadro III}

2) S1 e S2 são sujeitos complementares na estrutura de manipulação primária: S1 só obtém o lucro se S2 comprar o produto. S1 é sempre o sujeito manipulador e $\mathbf{S} 2$ o sujeito manipulado. Este último assume os papéis temáticos de comprador e consumidor, na estrutura de manipulação primária; todavia, o esquema só retrata o percurso de $\mathrm{S} 2$;

3) S2 e S3 são sujeitos complementares na estrutura de manipulação secundária: S2 só consegue a sua performance mítica se S3 comprar ou consumir o produto anunciado. Na estrutura de manipulação secundária, que se realiza através de debreagens internas, S2 é o sujeito manipulador e S3, o manipulado (S1 manipula S2, para que S2 manipule S3). Essa estrutura de manipulação secundária se instaura quando um dos sujeitos (S2 ou S3) não tem a competência segundo o querer/o poder/o sabcr-fazer/ter/ser; 
4) O arcabouço narrativo é o simulacro de um microssistema econômico, do ponto de vista do comprador e/ou consumidor. Ele permite a inscrição dos sujeitos em diferentes topos, de acordo com a competência inicial de cada ator/ sujeito ( $\approx$ figura nuclear complexa) e possibilita uma melhor compreensão dos procedimentos de figurativização.

Em seguida, passaremos à comparação entre figuras de atores-sujeitos para mostrar como o jogo semântico de superfície conduz o procedimento de figurativização e iconização. Tomaremos quatro textos-ocorrência que recontextualizam a mesma figura lexemática: a mulher. Para o entendimento da cena textual, todavia, é necessário considerarmos duas coisas:

1)o problema da implicitação: de acordo com o Groupe D’Entrevernes (1979: 125), «quando um conjunto figurativo ganha autonomia, basta uma só figura para recordá-lo». No texto publicitário, os formantes plásticos (ou figuras) que mostram a conjunção do sujeito manipulado com os objetos-valor. (S2 Ov), alude por anáfora a todo o percurso figurativo que recobre as quatro fases do PN de S2. Podemos dizer que a figura visual do sujeito (S2) realizado condensa todo o percurso narrativo proposto no contrato;

2) o problema da manipulação e identificação espelhada: enquanto espetáculo, o discurso publicitário é operador de uma dupla manipulação e de uma identificação através de um processo de espelhamento. Pela dupla manipulaçāo, o discurso opera, por meio do seu impacto visual, a transformação do não-leitor em leitor. Em seguida, uma vez seduzido ou provocado (querer-fazer ou não poder-não fazer + dever-fazer, respectivamente), ocorre uma segunda transformação, ou seja, de comprador e/ou consumidor virtual passa a comprador e/ou consumidor atual (atual, porque trata-se aqui da performance modal, da instauração de um contrato). Essa segunda transformação se dá graças ao processo de identificaçāo espelhada, de acordo com Lopes (1987: 87 a 89), pelo qual os leitores reais se identificam,através dos mecanismos de embreagem cognitiva, com os seus simulacros construídos que sã̃o os atores-personagens do texto.

Feitas essas duas observaçōes, voltemos aos textos-ocorrência e à figura da mulher, lcmbrando que os atores da cena enunciada são simulacros de atores reais: eu e você, que lemos o anúncio.

Com relação aos traços semânticos dos atores (Quadro IV), observa-se o seguinte:

1) o único traço comum a todas as figuras-mulher é o traço / feminilidade/; 


\begin{tabular}{|c|c|c|c|c|c|c|}
\hline TEXTO & \multicolumn{2}{|c|}{$\begin{array}{c}\text { COMPETÉNCIA INICIAL } \\
\text { DE S2 (S2 } 20 v)\end{array}$} & \multicolumn{2}{|c|}{$\begin{array}{l}\text { VALORES } \\
\text { INVESTIDOS NO } \\
\text { OBJETO }\end{array}$} & \multicolumn{2}{|c|}{$\begin{array}{l}\text { COMPETÉNCIA (S2nOv) FINAL DE S2 } \\
\text { APÓS A PERFORMANCE PRÁTICA E } \\
\text { MITICA }\end{array}$} \\
\hline & ATOA & /bom gosto/ & ATOA & & ATOR & \\
\hline $\begin{array}{c}1 \\
\text { Du } \\
\text { Maurier } \\
\text { (Fig.6) }\end{array}$ & 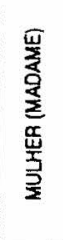 & $\begin{array}{l}\text { /status/ } \\
\text { /requinte/ } \\
\text { /discernimento/ } \\
\text { /beleza/ } \\
\text { / /legaincia/ } \\
\text { /sensibilidade/ } \\
\text { /felicidade/ }\end{array}$ & 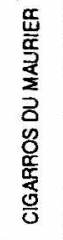 & $\begin{array}{l}\text { Irequinte/ } \\
\text { Imagicidade/ }\end{array}$ & 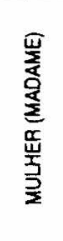 & /intensificaçāo da felicidade/ \\
\hline $\begin{array}{c}2 \\
\text { Gerber } \\
\text { (Fig.7) }\end{array}$ & . & $\begin{array}{l}\text { /feminilidade/ } \\
\text { |responsabilidade/ } \\
\text { /instinto maternal/ } \\
\text { /nāo-dedicação/ } \\
\text { /não-alegria/ } \\
\text { /näo-praticidade/ }\end{array}$ & 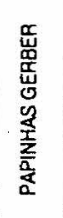 & $\begin{array}{l}\text { Inutritiva/ } \\
\text { /saudável/ } \\
\text { /prática/ }\end{array}$ & & $\begin{array}{l}\text { /alegria/ } \\
\text { /dedicaçäo/ } \\
\text { /liberdade/ }\end{array}$ \\
\hline $\begin{array}{c}3 \\
\text { Whisky } \\
\text { John } \\
\text { Pitt } \\
\text { (Fig.8) }\end{array}$ & 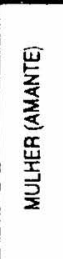 & $\begin{array}{l}\text { /emancipaçāo/ } \\
\text { /rejeiçäo/ } \\
\text { /não-sedutora/ } \\
\text { /feminilidade/ }\end{array}$ & 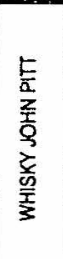 & $\begin{array}{l}\text { /pureza/ } \\
\text { Irequinte/ } \\
\text { /magicidade/ }\end{array}$ & 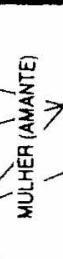 & $\begin{array}{l}\text { /seduçāol } \\
\text { /amor/. }\end{array}$ \\
\hline $\begin{array}{c}4 \\
\text { Charm } \\
\text { (Fig. } 9 \text { ) }\end{array}$ & 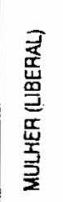 & $\begin{array}{l}\text { /feminilidade/ } \\
\text { /elegāncia/ } \\
\text { /beleza/ } \\
\text { /nāo-seduçāo/ } \\
\text { /nāo-charme/ }\end{array}$ & 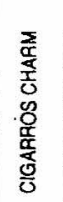 & /magicidade/ & 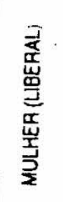 & $\begin{array}{l}\text { /charme/ } \\
\text { /seduçäo/ }\end{array}$ \\
\hline
\end{tabular}

\section{Quadro IV}

2) os traços /discernimento/ e /elegância/ são comuns às

mulheres dos anúncios dos cigarros Charm e Du Maurier.

De acordo com Assis (1987:53), "o trabalho textual consiste na reconfiguração da parte variável de uma figura lexemática ou discursiva, em termos de uma sintaxe actancial, resultante da realizaçāo de um $P N^{\prime \prime}$. Essa reconfiguração, ainda segundo o autor, pode incidir sobre o genérico ou o específico $\mathrm{e}$ 
deve ser encarada à luz de uma tipolo gia discursiva.

Tendo em vista a permanência de traços das figuras-ator, apresentadas nessa pequena amostra (figs.6, 7 , 8 e 9), é possivel afirmar que:

- 1) no universo do discurso publicitário, essa reconfiguração incide, predominantemente, sobre a parte específica do semema do ator, e raramente sobre a parte variável genérica. Dentre os textos citados neste artigo, apenas dois deles apresentam reconfiguração do classemático: os textos do Catchup Etti (fig.10) e os da Coca Cola (fig. 11);

2) à medida que certos traços contextuais se incorporam à figura em
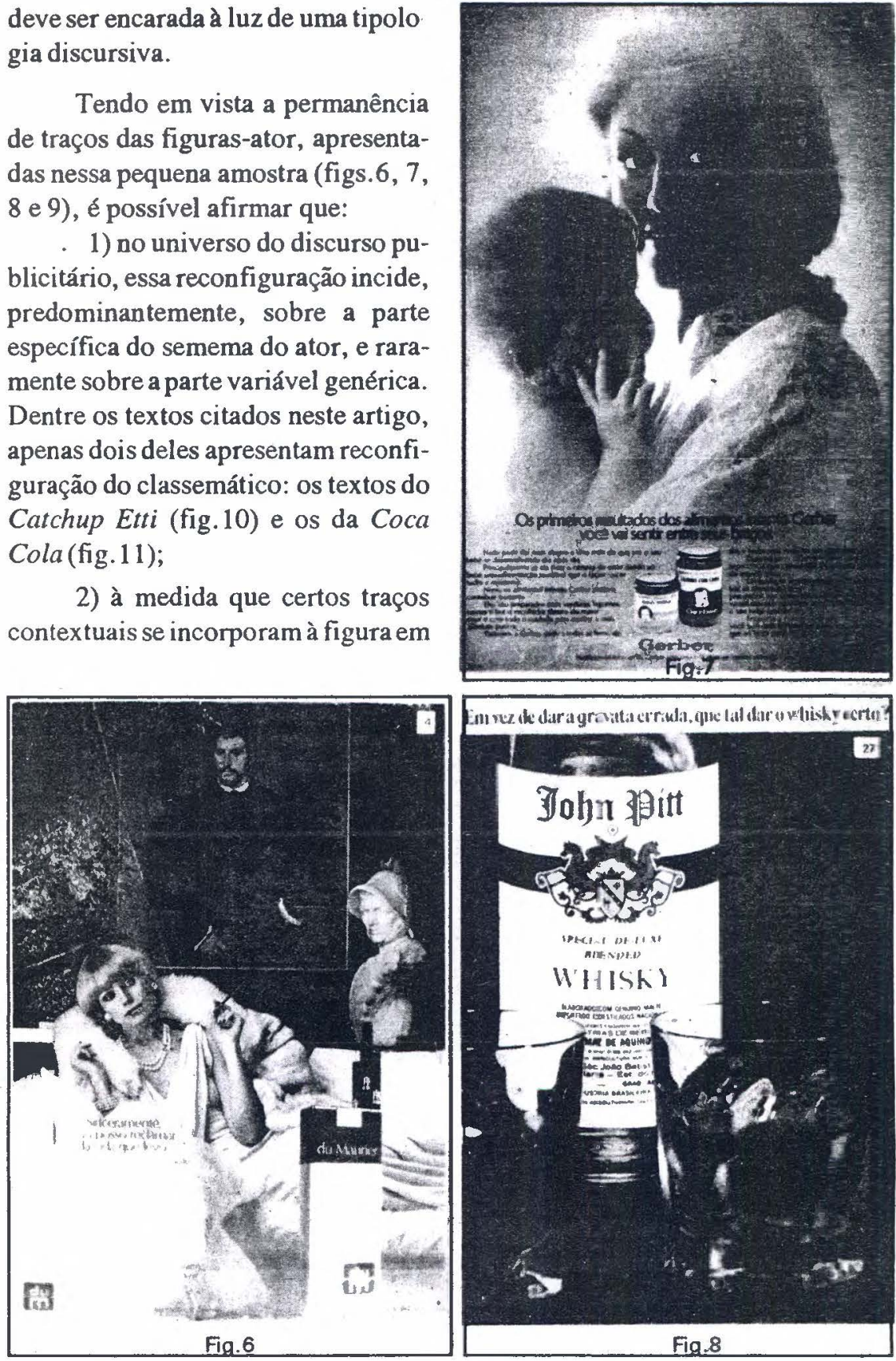
estado de dicionário e são realizados em contextos específicos, tais traços (tais como/discernimento/ e/elegância/, in Charm e Du Maurier), se incorporam à base classemática, enquanto definidores de uma subclasse de figuras.

Desta maneira, é o rearranjo de semas contextuais (rearranjo figurativo) que vai gerar figuras ligeiramente diferenciadas - figuras no sentido narratológico, as quais, segundo Floch (1983:5), provêm da substância c̀ não da forma.

Esse rearranjo obedece a dois procedimentos:

a) o da intensilicaçáo de tracos semainticos, podendo estes atingirem o seu grau máximo de iconicidade (cf. fig.8, referentementc ao) traço semuântico/felicidade/);

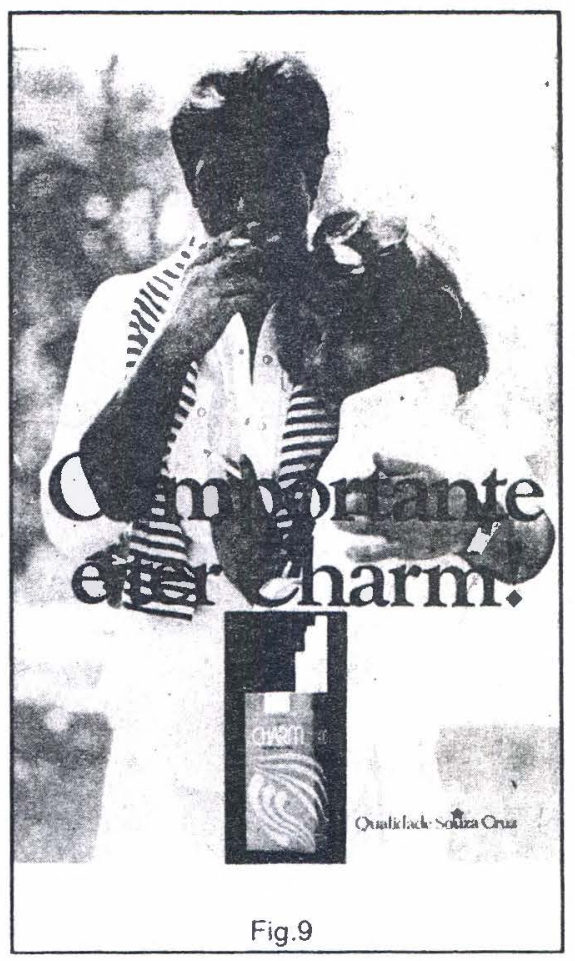

b) o da substituição de traços semânticos por seus contrários ou contraditórios combinados ou nảo com traços complementares (relação de implicação).

O rearranjo figurativo e condicionado pelo rearranjo classemático e subclassemático. Estes últimos, por sua vez, vāo gerar diferentes percursos temáticos:

Núcleo sêmico + (classemas + subclassemas) + semas contextuais

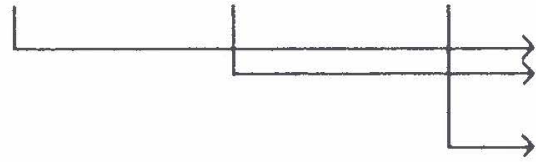

Novos temas

Variaçōes sobre o mesmo tema

$\rightarrow$ Novos percursos figurativos para o mesmo tema

Por último, abordaremos mais una vez os textos da Coca Cola (fig. 11) e do Catchup Etti (fig. 10) com a finalidade de chamar a atençāo para um aspecto da problemática da construçảo discursiva e textual dó ator. 
Citando novamente Assis (1985: 575-582), a construção discursiva e textual do ator pode ser vista sob duas hipóteses: «aquela, segundo a qual a figura seria construida como um estado, como um lugar sêmio-discursivo predominantemente aspectual» e *aquela, segundo a qual a figura uma vez elevada, pelos procedimentos discursivos, ao estatuto de figura narratológica, de figura-ator, apareceria como lugar por excelência da constituição e da intersemioticidade, como uma instância semi-simbólica onde a disjunção mundo natural/lingua natural se veria concretizada*.

Considerando que, na conversão discursiva das estruturas narrativas, as funções-predicados resultam em processos e as funções-junçôes em estados, nossa primeira observação recaí sobre a possibilidade de se trabalhar a figurativização da função predicado e da função-junção também no âmbito da relação objeto-valor, pois parece-nos que a figurativização dessas funções é vista, pela maioria dos estudiosos, somente no âmbito da relação sujeito-objeto. Desta maneira, propõe-se extrapolar as relações actanciais intencionais e existenciais para as transformações e junções relativas ao investimento do valor no objeto. Cremos que os dois textos citados ilustram o que foi dito:

1) no texto da Etti (fig.10), o objeto (Catchup) apresenta-se como uma figura narratológica em que, na conversão da função-predicado (nível narrativo) em processo (nível discursivo), a aspectualização intervém como um ponto de vista sobre a ação, enfatizando o tempo: o aspecto opera como uma sobredeterminação temporal. Aqui, a figurativização do processo deixa visualizar o rearranjo

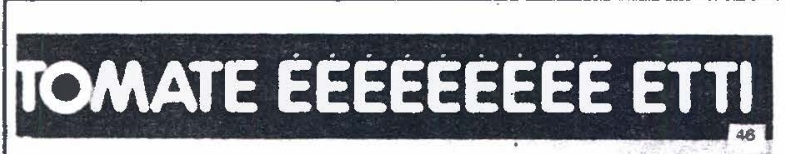
figurativo: o traço /artificial/ do estado 1 (do Catchup) pressuposto é substituído pelo traço /natural/, no estado 2.

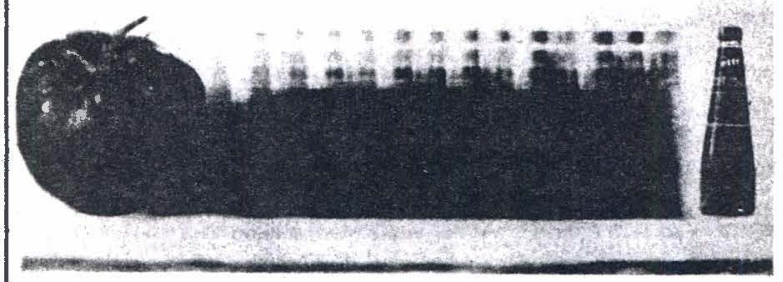

Fig. 10

Convém observar que este enunciado narrativo conta a produção de um objeto. Pertence ao percurso de S1 (sujeito enunciador-ma- 
nipulador) e se inscreve na fase de manipulaçāo do PN de base de S2. sob um duplo aspecto:

a) como instância de enunciação-enunciada, pois denuncia como o sujeito-enunciador investe $\mathrm{o}$ valor no objeto, mesmo que seja ao modo do parecer;

b) como objeto-valor: enquanto estado final, a figura do Catchup se erige em objeto-valor $c \dot{c}$, ao mesmo tempo, inscrita, pelo sujeito enunciador, no percurso de S2;

2) no texto da Coca Cola (fig.11), os atores-objetos -o prático (coca cola) e o mítico (estilo de

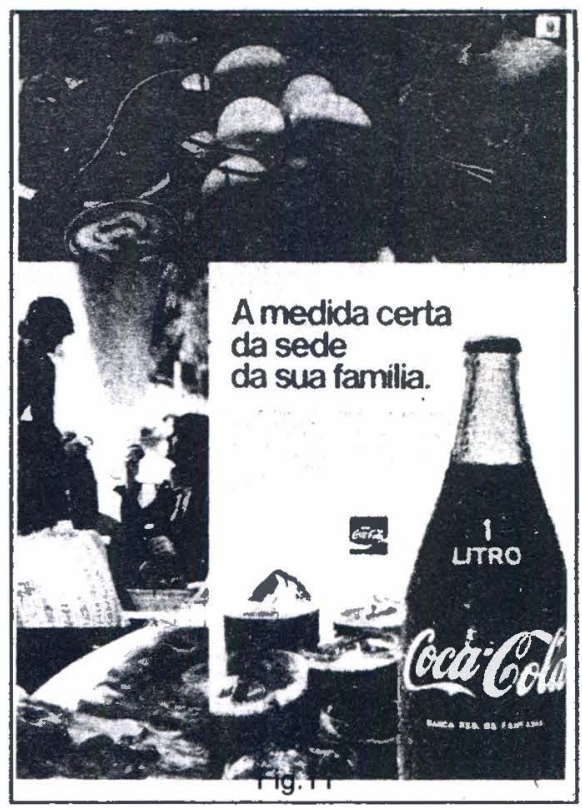
vida) - são constituidos como um estado. Na conversão da função-junção (na relação objeto-valor) a aspectualização intervém como um ponto de vista sobre o estado, em que as consideraçóes temporais ficam entre parènteses, nos clizeres de Assis (op.cit.).

A segunda observação di\% respeito à hipótese da construçāo da figura como um estado. Neste caso, a colocação entre parêntescs do tempo traz sérias dificuldades para a comprecensão da figuratividade do visual quando se trata de textos miticos c poéticos. É o que se observa no texto da Coca Cola, onde a aspectualização do espaço (considerando a superfícic global do texto) «apaga» as referencializaçōes internas entre os diferentes segmentos do texto visual e, conseqüentementc, nāo figurativiza as transformações de estado com referência ao objeto coca-cola; cste sof re uma transformação, ou seja, passa de um estado signico - enquanto «alimento»- a um estado simbólico, enquanto/ser que dá vida/, uma vez que essa figura-ator sofre um rearranjo classemático. Esse rearranjo, todavia, não se dá numa perspectiva narratológica, pela colocação cm andamento de um PN, e sim pela depreensão de traços da expressão visual c verbal que sustentam esse discurso abstrato: a ideia de que "Coca-Cola dá (mais) vida» e a sugestão para que o consumidor mude o seu "estilo de vida».

Nesse texto, os traços do objeto com função prática estão explicitados 
pelo texto verbal. Já os traços com função mítica /nutritiva/e /que dá vida/ estão dissimulados pelos procedimentos de enunciação, pois trata-se de um saber enganoso acerca do valor do objeto. $\mathrm{Na}$ análise deste texto, o caminho para se chegar a esse saber enganoso é utilizar os procedimentos de análise da semiótica plástica.

Tendo em vista que o.texto publicitário propõe sempre dois objetos - um objeto com valor prático e outro objeto com valor mítico- no texto da CocaCola ambos estão explicitados no verbal; a figurativizaçẳo, no visual, diz respeito, portanto, à refuncionalização do objeto coca-cola:

$$
\begin{aligned}
& \text { Estadol } \quad \text { Estado 2 } \\
& \text { /artificial/ }+\ldots \text {-..-->natural/ + /nutritiva/ + /que dá vida/ }
\end{aligned}
$$

Embora não seja possível demonstrar aqui a construção do sentido, neste texto, podemos afirmar que é somente pela análise dos componentes eidéticos, cromáticos e topológicos do visual e do verbal que se pode:

a) apreender os valores investidos no objeto prático (coca-cola), que são os traços descritos acima no estado 2;

b) homologar a construção do objeto mítico, sugerido em ambos os códigos, que é estilo de vida.

Pouco, ainda, se pode falar do percurso gerativo da expressão. Contudo, parece certo que, neste texto, a figurativização - que resulta na construção do objeto mítico e na refuncionalização do objeto prático - se dá, simultaneamente, nos dois percursos gerativos: o da expressão e o do conteúdo. Tal afirmação, é óbvio, requer uma análise mais prècisa, utilizando-se instrumentos da semiótica plástica. Entretanto, fica-nos a idéia de que:

a) só podemos falar em percurso gerativo da expressão nas linguagens conotadas, quando há a sobreposição de planos de expressão e de conteúdo que, juntos, funcionam como forma de expressão para um novo e último conteúdo;

b) essa forma de expressão, jogando com categorias eidéticas, to pológicas e cromáticas, no texto plástico, talvez seja suscetível de ser matematicamente formulável, por meio de homologa- 
ções sucessivas entre quartas proporcionais - pois a geração do sentido da expressão parece prescrever um ritmo que obedece a uma topologia bem determinada. Assim, o percurso gerativo da expressão do texto plástico (visual e verbal) constituir-se-ia numa sobreposição hierárquica de sistemas semi-simbólicos.

A título de conclusão, nosso objetivo foi dar uma idéia de como ocorre a figurativização/figuratividade no discurso publicitário a partir da seleção do(s) valor(es) da estrutura profunda, procurando mostrar que o jogo de imagens e figuras de um texto só pode ser compreendido e avaliado em funçăo do nexo existente entre as instâncias semio-narrativa e discursiva.

Todavia, em discursos altamente redundantes que podem abusar da implicitação, como o publicitário, só é possível estabelecer esse nexo a nível de uma tipologia discursiva e não a nível de textos-ocorrència, lembrando que:

- a nível discursivo, podem-se criar relações de metáfora e metonímia quando vários conjuntos figurativos se conectam com o mesmo momento narrativo, fazendo uma figura valer por outra;

- nos textos poéticos, para a compreensão da figuratividade, há que se considerar, também, o percurso gerativo da expressão: quando o sujeito enunciador não se pode valer de um dicionário figurativo, procura criar novos percursos figurativos através de procedimentos semi-simbólicos. No texto publicitário, tais procedimentos conduzem sempre a um saber enganoso relativo à construção do objeto mítico ou ao valor investido no objeto;

- como disse Floch (op.cit.), «por mais que as figuras estejam recheadas de traços figurativos, elas não são uma imagem do mundo", no texto publicitário pode-se afirmar com certeza que elas simulam uma representação do mundo para cumprir a sua função de persuasão - função que, muitas vezes, ocorre através de figuras (não-signos) da expressão, que se tornam significantes e passam a sustentar um discurso abstrato, como é caso do texto da Coca-Cola.

E, por último, uma dúvida: tendo em vista a reconfiguração de traços contextuais (cf.fig. 2 e 3), através de procedimentos metafóricos ou metonímicos, as metáforas e metonímias poderiam ser pensadas como instrumentos de iconização das figuras abstratas do plano de conteúdo? 


\section{BIBLIOGRAFIA}

FLOCH, J-M. "Figures, iconicité et plasticite" in: Actes sémiotiques Bulletin, VI - ENESS-CNRS, Paris, INFL, 1983.

GREIMAS, A. J. \& COURTÈS, J. Sémiotique - dictionnaire raisonné de la . théorie du langage II. Paris, Classiques Hachette, 1986.

. Diconário de semiótica. São Paulo, Cultrix, 1983.

GROUPED'ENTREVERNES. Analyse sémiotique des textes.Lyon, Presses Universitaires de Lyon, 1979.

LOPES, E. A metáfora: da retórica à semiótica. São Paulo, Atual, 1986.

LUCA, LEONILDA RANZANI de. Aspectos da semiótica do discurso publicitário.São Paulo, FFLCH-USP, tese de doutorado, 1983 (mimeografado).

SILVA, I. A. da. "La construction de l'acteur" in: Parret, N \& Ruprecht, H. G. - Exigences et perspectives de la sémiotique: recueil d'homage pour A. J. Greimas. Amsterdam/ Philadelphia, John Benjamins, 1985, pp. 575-582.

. "A construção do ator: do signico ao simbólico" in: Significação - Revista Brasileira de Semiótica, 6 janeiro de 87, pp. 51-57. 